\title{
EROSION AND ACCRETION ON CURVED BEACH
}

\author{
Kideok Do ${ }^{1}$, Nobuhisa Kobayashi ${ }^{2}$ and Kyung-Duck Suh ${ }^{3}$
}

\begin{abstract}
The performance of a large nourishment project on Bethany Beach, Delaware is evaluated using available beach profile, wave and tide data during September 2007 to September 2010. The volume of the placed sand with the median diameter of $0.31 \mathrm{~mm}$ was about $500 \mathrm{~m}^{3} / \mathrm{m}$ along the curved shoreline of $1.8 \mathrm{~km}$ length. The nourished beach was attacked by two severe storms in May 2008 and November 2009. The eroded sand volume above the mean sea level (MSL) was about $70 \mathrm{~m}^{3} / \mathrm{m}$ for each of the two storms and emergency repairs were necessary. The numerical cross-shore model with multiple cross-shore lines is used to compute the cross-shore and longshore sediment transport. The beach erosion above MSL is shown to be caused by the offshore sand transport and the alongshore gradient of the longshore sand transport rate. The performance of the nourished beach is predicted to be sensitive to the sand diameter in the range of 0.23 to $0.45 \mathrm{~mm}$.
\end{abstract}

Keywords: Beach; Sand; Nourishment; Storm; Erosion; Waves; Currents

\section{Introduction}

The Atlantic sandy coast in Delaware is suffering from chronic beach erosion. A wide beach with a high dune is maintained by periodic beach nourishment in order to provide coastal storm protection and flooding damage reduction (U.S. Army Engineer Research and Development Center 2002). The performance of the four nourished beaches in Delaware during 1998 to 2005 was analyzed by Figlus and Kobayashi (2008) using surveyed beach profiles and available tide and wave data. The analysis indicated the importance of both cross-shore and longshore sediment transport to explain the evolution of these nourished beaches with large variabilities in time and space.

This study analyzes the performance of the beach nourishment project on Bethany Beach in Delaware during 2007 to 2010. The U.S. Army Corps of Engineers surveyed 13 beach profiles spanning an alongshore distance of approximately $1,800 \mathrm{~m}$. The nourished sand volume per unit alongshore length was about $500 \mathrm{~m}^{3} / \mathrm{m}$. Severe storms attacked Bethany Beach in May 2008 and November 2009. These storms eroded the nourished sand down to the elevation of the beach profile before the nourishment at some locations above the mean sea level (MSL). The erosion volume above MSL per unit alongshore length was about $70 \mathrm{~m}^{3} / \mathrm{m}$ for each of the two storms. In addition to the surveyed beach profiles and available tide and wave data, a numerical model is required to estimate the sediment transport pattern on Bethany Beach with a curved shoreline.

The cross-shore numerical model CSHORE is applied to compute the cross-shore and longshore sediment transport rates (Kobayashi et al. 2009). The effect of the alongshore gradient of the longshore sediment transport rate on the beach profile evolution was included in CSHORE by Kobayashi and Jung (2012). This effect is expected to be important for the curved beach. The numerical model is expanded in this study to include the effects of tidal currents and infiltration landward of the dune crest. The cross-shore tidal current associated with the temporal variation of the water level is known to be important for the cross-shore sediment transport on an intertidal flat (e.g., Yamada and Kobayashi 2007). The alongshore tidal current driven by the alongshore gradient of the water level modifies the wave-induced longshore current and sediment transport on a beach (Farhadzadeh et al. 2012). Infiltration is important for sediment transport on a gravel beach (e.g., Kobayashi et al. 2011) but is normally neglected for a sand beach. These effects on the sediment transport on Bethany Beach are quantified in this study. In addition, the sensitivity of the nourished beach to the placed sand size is examined using the numerical model which is shown to reproduce the beach profiles surveyed after the two storms.

In the following, field data are presented first. The effects of the tidal currents and infiltration added to the numerical model are explained concisely. The expanded numerical model is compared with the field data and the added effects are quantified to assess their importance for Bethany Beach. The performance of the nourished beach is evaluated for hypothetical sands whose diameters are about

\footnotetext{
${ }^{1}$ Korea Ocean R\&D Institute, Ansan, Gyeonggi, 426-744, Republic of Korea \& Dept. of Civil and Environmental Engineering, Seoul National Univ., 1 Gwanak-ro, Gwanak-gu, Seoul, 151-744, Republic of Korea.

${ }^{2}$ Center for Applied Coastal Research, Univ. of Delaware, Newark, DE 19716.

${ }^{3}$ Dept. of Civil and Environmental Engineering, Seoul National Univ., 1 Gwanak-ro, Gwanak-gu, Seoul, 151-744, Republic of Korea.
} 
30 percent larger and smaller than the actual sand used for the beach nourishment on Bethany Beach. This paper presents the essential parts of the report by Do et al. (2012).

\section{Field Data}

Bethany Beach is located along the Atlantic sandy coast in Delaware. The U.S. Army Corps of Engineers measured beach profiles along 13 survey lines called N00 to N60 in Fig. 1. The distance between the two adjacent lines along the curved shoreline is approximately $150 \mathrm{~m}$. The beach profiles were surveyed seven times from 15 September 2007 to 15 September 2010. The annual monitoring surveys were conducted in September. The six periods between the two successive surveys in Table 1 are characterized by the capital letters $\mathrm{N}$ (nourishment), E (erosion above MSL), and A (accretion above MSL) as well as the numerals 1 (first), 2 (second), and 3 (third). The start date and number of days in each period are listed in Table 1. The initial and final profiles for period N1 were surveyed before and after the major nourishment on Bethany Beach. The final profile for N1 is the initial profile for erosion period E1 whose final profile was surveyed after the Mother's Day storm in 2008. The eroded initial profile for accretion period A1 recovered somewhat by the fall survey in 2008. Minor nourishment was carried out to repair the eroded profile above MSL during nourishment period N2. The final profile of erosion period E2 was surveyed after the second severe storm in November 2009. The eroded dune was repaired and some natural recovery occurred during the nourishment period N3.

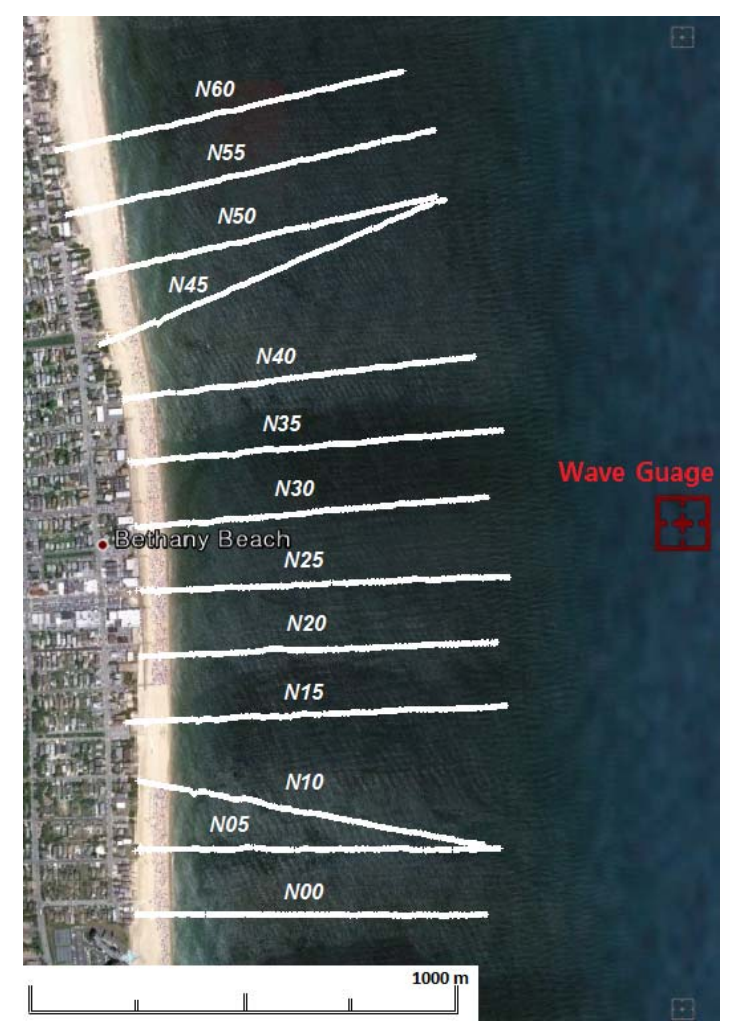

Figure 1. Bethany Beach, 13 survey lines (N00 to N60), and Wave Gauge DE002.

For the duration of the seven profile surveys, a wave gauge (DE002 in Fig. 1) was located at a depth of about $10 \mathrm{~m}$ off the coast of Bethany Beach. The hourly time series of the spectral significant wave height $H_{m 0}$, spectral peak period $T_{P}$, and peak spectral wave direction $\theta_{P}$ (in degrees clockwise from the true north) are available. The hourly time series of the water level S above MSL is available at the tide gauge at Lewes, Delaware which is located $28 \mathrm{~km}$ north of Bethany Beach. The average values of $S, H_{m 0}, T_{P}$ and $\theta_{P}$ for each period are listed in Table 1 . The average value of $H_{m 0}$ was larger during periods E1 and E2. The average wave angles for all the periods were less than the easterly wave 
of $90^{\circ}$. The incident waves from the north and east quadrant occurred more frequently than those from the east and south quadrant.

\begin{tabular}{|c|c|c|c|c|c|c|}
\hline \multirow[b]{2}{*}{ Period } & \multirow[b]{2}{*}{ Start Date } & \multirow[b]{2}{*}{$\begin{array}{l}\text { Number } \\
\text { of Days }\end{array}$} & \multicolumn{4}{|c|}{ Average during Each Period } \\
\hline & & & $S(\mathrm{~m})$ & $H_{m 0}(\mathrm{~m})$ & $T_{P}(\mathrm{~s})$ & $\begin{array}{c}\theta_{P} \\
\text { (degrees) }\end{array}$ \\
\hline N1 & 15 September 2007 & 166 & 0.03 & 0.69 & 8.3 & 80.5 \\
\hline E1 & 28 February 2008 & 177 & 0.08 & 0.82 & 8.3 & 77.4 \\
\hline A1 & 15 May 2008 & 137 & 0.09 & 0.62 & 8.6 & 89.6 \\
\hline N2 & 30 September 2008 & 349 & 0.06 & 0.67 & 8.3 & 82.6 \\
\hline E2 & 14 September 2009 & 88 & 0.23 & 0.88 & 8.4 & 70.5 \\
\hline N3 & 11 December 2009 & 278 & 0.11 & 0.65 & 8.7 & 83.7 \\
\hline
\end{tabular}

The characteristics of the 13 survey lines are shown in Table 2 where the coordinate $y$ is the northward distance along the curved shoreline from line N00 to be consistent with the increase of the numeral from N00 to N60 in Fig. 1. The cross-shore distance $x_{m}$ for each line is obtained from the overlapping zone of the seven surveyed profiles where the onshore coordinate $x$ along the cross-shore line is taken as $x=0$ at its seaward limit of the overlapping zone. The azimuth of each line is the angle in degrees clockwise from the true north. Lines N10 and N45 are not normal to the curved shoreline. The northward decrease of the azimuth causes the alongshore variation of the wave-induced longshore sediment transport rate. The nourished sand volume per unit alongshore length is the area between the final and initial profiles in the entire overlapping zone for period N1. The nourished sand volumes varied in the range of 279 to $654 \mathrm{~m}^{3} / \mathrm{m}$. The average volume of $496 \mathrm{~m}^{3} / \mathrm{m}$ was much larger than 144 $\mathrm{m}^{3} / \mathrm{m}$ placed on Bethany Beach in 1998 (Figlus and Kobayashi 2008). The erosion volumes per unit alongshore length above MSL for periods E1 and E2 are obtained from the initial and final profiles of each erosion period. The average erosion volume above MSL was $74 \mathrm{~m}^{3} / \mathrm{m}$ for E1 and $70 \mathrm{~m}^{3} / \mathrm{m}$ for E2. These two erosion periods are described in more detail.

\begin{tabular}{|c|c|c|c|c|c|c|}
\hline \multirow{2}{*}{ Line } & \multirow{2}{*}{$\begin{array}{c}\text { Alongshore } \\
\text { Distance } \\
y(\mathrm{~m})\end{array}$} & \multirow{2}{*}{$\begin{array}{c}\text { Cross-shore } \\
\text { Distance } \\
x_{m}(\mathrm{~m})\end{array}$} & \multirow{2}{*}{$\begin{array}{l}\text { Azimuth } \\
\text { (degrees) }\end{array}$} & \multirow{2}{*}{$\begin{array}{c}\text { Nourished } \\
\text { Volume } \\
\left(\mathrm{m}^{3} / \mathrm{m}\right)\end{array}$} & \multicolumn{2}{|c|}{$\begin{array}{c}\text { Erosion Volume } \\
\text { above MSL }\left(\mathrm{m}^{3} / \mathrm{m}\right)\end{array}$} \\
\hline & & & & & E1 & E2 \\
\hline N00 & 0 & 383 & 89.9 & 628 & 75 & 68 \\
\hline N05 & 152 & 442 & 89.9 & 594 & 77 & 74 \\
\hline N10 & 296 & 373 & 100.2 & 569 & 90 & 97 \\
\hline N15 & 456 & 408 & 87.4 & 654 & 98 & 95 \\
\hline N20 & 609 & 349 & 87.4 & 544 & 86 & 61 \\
\hline N25 & 762 & 407 & 87.4 & 515 & 75 & 69 \\
\hline N30 & 915 & 425 & 84.7 & 557 & 83 & 55 \\
\hline N35 & 1069 & 538 & 84.7 & 550 & 75 & 101 \\
\hline N40 & 1222 & 471 & 82.9 & 461 & 73 & 123 \\
\hline N45 & 1382 & 534 & 66.6 & 404 & 70 & 45 \\
\hline N50 & 1529 & 530 & 76.8 & 376 & 56 & 80 \\
\hline N55 & 1681 & 585 & 76.8 & 315 & 64 & 20 \\
\hline $\mathrm{N} 60$ & 1833 & 694 & 76.8 & 279 & 43 & 25 \\
\hline & & & Average & 496 & 74 & 70 \\
\hline
\end{tabular}

Fig. 2 shows the time series of $S, H_{m 0}, T_{P}$ and $\theta_{P}$ for the 2008 Mother's Day storm where the abscissa is the number of days since 10 May 2008. The horizontal line in each panel is the average value listed in Table 1. The peak of the water level exceeding $1.5 \mathrm{~m}$ occurred before the peak of the significant wave height exceeding $3 \mathrm{~m}$. The wave period fluctuated around the average value. The incident waves came from the northeast. The storm duration was about 1.5 days. This storm was not very extreme but the beach erosion was large because the storm attacked soon after its major nourishment. Fig. 3 shows the initial and final profiles of period E1 along line N30 in Fig. 1. Line N30 is used as an example in this and subsequent figures because it is located in the middle of the 13 survey lines. The initial profile of period N1 corresponds to the profile before the major nourishment. The offshore zone of the negligible profile change is omitted in this and subsequent figures. The storm eroded the nourished berm above MSL but the nourished dune was almost intact. The comparison 
between the initial and final profiles of period E1 in Fig. 3 indicates the sand volume loss of $36 \mathrm{~m}^{3} / \mathrm{m}$ which was probably caused by the gradient of the longshore sediment transport rate. This sand volume loss is examined later using the numerical model.
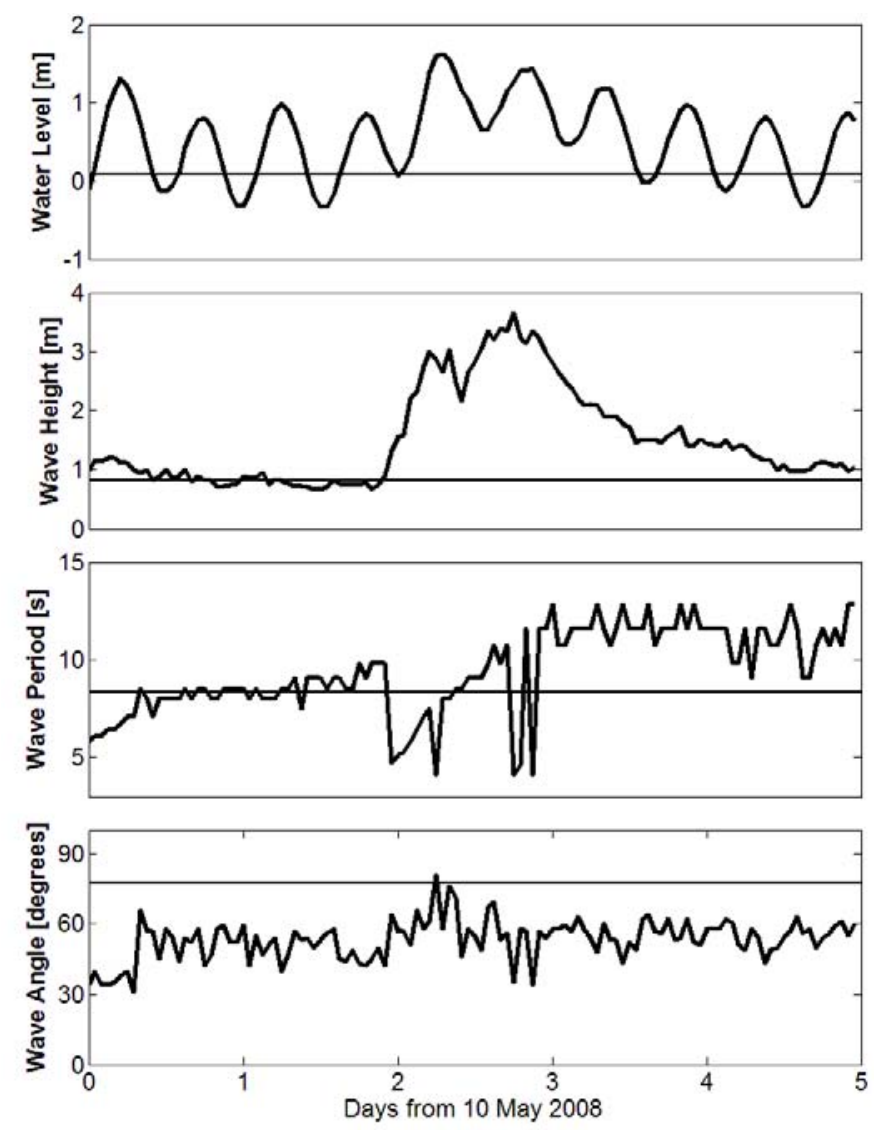

Figure 2. Water level, significant wave height, spectral peak period, and peak spectral wave direction during 2008 Mother's day storm.

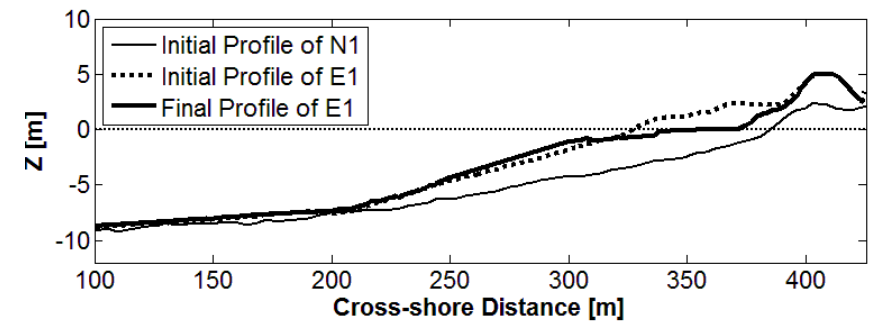

Figure 3. Initial and final profiles of period E1 above initial profile of period N1 along line N30.

Fig. 4 shows the time series of $S, H_{m 0}, T_{p}$ and $\theta_{p}$ for the November 2009 storm which lasted more than 3 days. The water level exceeded $1.5 \mathrm{~m}$ during two high tides. The significant wave height exceeded $3 \mathrm{~m}$ for almost 2 days. The wave period fluctuated around the average value. The incident waves came mostly from the northeast. This storm was more severe than the May 2008 storm. Fig. 5 shows the initial and final profiles of period E2 and the initial profile of period N1 along line N30. The berm and dune were eroded but the dune was not destroyed except for line N40. The downward erosion above MSL reached to the berm elevation before the major nourishment. The eroded beach profile below MSL was well above the beach profile before the nourishment. The nourished beach withstood the two severe storms which occurred at an interval of 1.5 years. The small accretion above 
MSL during period A1 and the minor repair above MSL during period N2 may have contributed somewhat to the survival of the dune during the November 2009 storm.
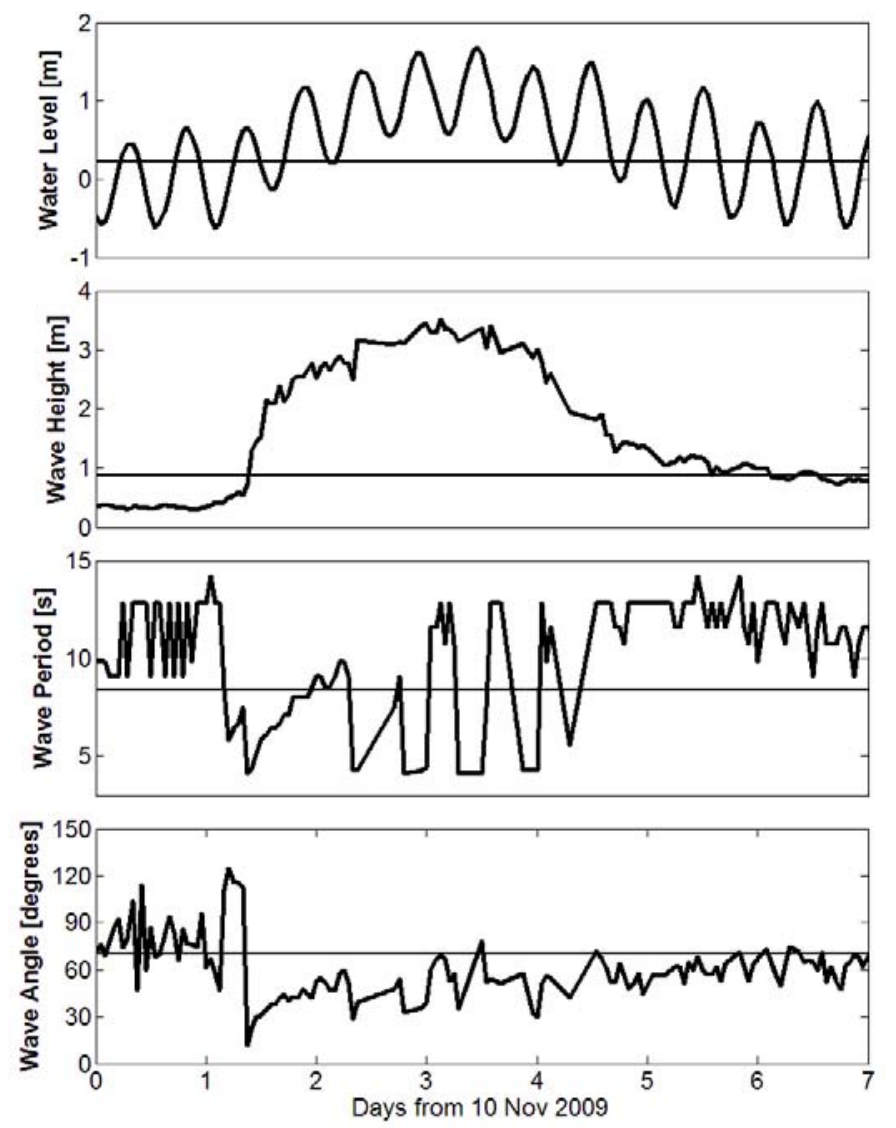

Figure 4. Water level, significant wave height, spectral peak period, and peak spectral wave direction during November 2009 storm.

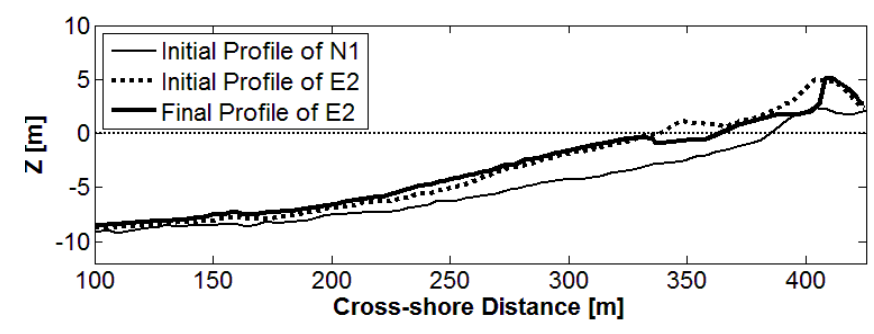

Figure 5. Initial and final profiles of period E2 above initial profile of period N1 along line N30.

The performance of the nourished beach against the two storms depended on the characteristics of the sand which was dredged offshore and placed on Bethany Beach. Dean (1991) analyzed the profile response to beach nourishment using equilibrium beach profiles for native and placed sands. Table 3 summarizes the placed sand characteristics. The median diameter is $0.31 \mathrm{~mm}$. The diameters corresponding to the 16 and 84 percent finer by weight are 0.23 and $0.45 \mathrm{~mm}$, respectively. The fall velocity for each diameter is estimated using the formula for natural sediments proposed by Jiménez and Madsen (2003) where the specific gravity of the sediment in sea water is assumed to be 2.6. This medium sand is well sorted and similar to the native sand on Bethany Beach (Ramsey 1999). The numerical model CSHORE represents the sand by its median diameter and corresponding fall velocity (Kobayashi et al. 2009). The sensitivity of the profile response to this representative diameter is examined later for future nourishment projects. 


\begin{tabular}{|c|c|c|c|}
\hline Percent Finer by Weight & 16 & 50 & 84 \\
\hline Diameter (mm) & 0.23 & 0.31 & 0.45 \\
\hline Fall Velocity $(\mathrm{cm} / 2)$ & 2.85 & 4.17 & 6.26 \\
\hline
\end{tabular}

Additional input is required to estimate the tidal currents added to the expanded numerical model. The cross-shore tidal current is related to the temporal variation of the water level $S$. The hourly time series of $S$ at the Lewes tide gauge is used to compute the value of $\partial S$ / $\partial t$ with $t=$ time which oscillates in the range of -0.01 to $0.01 \mathrm{~cm} / \mathrm{s}$. The alongshore tidal current is assumed to be driven by the alongshore gradient of $S$. The tide gauge at Ocean City, Maryland is located $22 \mathrm{~km}$ south of Bethany Beach. The distance between the two tide gauges is $50 \mathrm{~km}$. The present tide gauge is located landward of the Ocean City inlet which reduces the water level oscillation. The tide gauge was located outside the inlet until 1991. The time series of the water levels measured at the past and Lewes tide gauges during November 1990 to October 1991 are compared to develop an empirical equation for the water level $S$ at Ocean City as a function of $S$ at Lewes. The water level at Ocean City was smaller and lagged approximately one hour. The correlation coefficient for this empirical equation is 0.99 . The water level at Ocean City during the six periods in Table 1 is estimated using the empirical equation to obtain the alongshore gradient of $S$. Fig. 6 shows the computed time series of the alongshore gradient $\partial S$ / $\partial y$ during period E2 as an example. The gradient is of the order of $10^{-5}$.

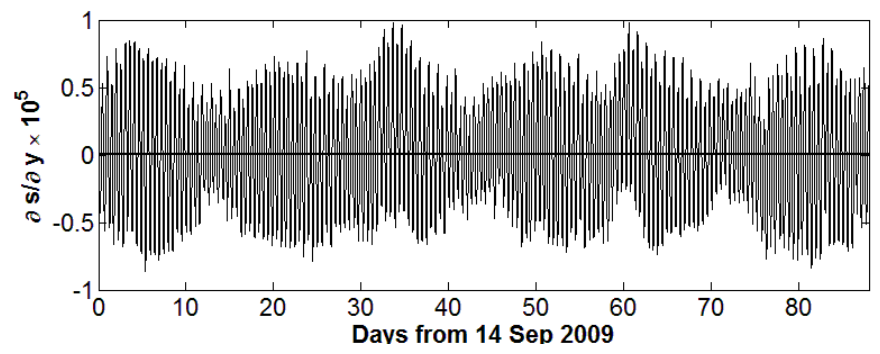

Figure 6. Time series of alongshore gradient of water level $S$ above MSL during period E2.

\section{Numerical Model}

The cross-shore numerical model CSHORE assumes unidirectional irregular waves and alongshore uniformity along each cross-shore line normal to the local shoreline. Lines N10 and N45 in Fig. 1 are excluded in the following computations because of their obliqueness. The input to CSHORE includes the hourly time series of the water level $S$ above MSL and the incident wave conditions represented by $H_{m 0}, T_{P}$ and $\theta$ at the seaward boundary $x=0$ in water depth of approximately $10 \mathrm{~m}$ where the incident wave angle at $x=0$ is the angle clockwise from the cross-shore line and obtained by subtracting the line azimuth in Table 2 from the wave angle $\theta_{p}$ measured at the wave gauge in Fig. 1. The beach sand is characterized by the median diameter of $0.31 \mathrm{~mm}$ and the fall velocity of 4.17 $\mathrm{cm} / \mathrm{s}$ where the bottom sediment porosity is assumed as 0.4 . The beach profile evolution along each cross-shore line is computed starting from the initial profile of the period with no beach nourishment (E1, A1 and E2 in Table 1). The alongshore gradient of the longshore sediment transport rate in the continuity equation of bottom sediment is taken into account approximately in the profile evolution computation (Kobayashi and Jung 2012). The modifications made in this study are explained in the following.

In the wet zone seaward of the still water shoreline located at $x=x_{S W L}$, the time-averaged continuity equation of water is expressed as 


$$
\frac{g \sigma_{\eta}^{2}}{C} \cos \theta+\bar{h} \bar{U}=q_{o}+q_{s} \quad ; \quad q_{s}=\left(x_{s W L}-x\right) \frac{\partial S}{\partial t} \text { for } x<x_{S W L}
$$

where $g=$ gravitational acceleration; $\sigma_{\eta}=$ standard deviation of the free surface elevation above the still water level $S$; $C=$ linear wave phase velocity based on $T_{p}$ in the mean water depth $\bar{h} ; \theta=$ wave angle clockwise from the onshore coordinate $x$ which is predicted using Snell's law; $\bar{U}=$ depth-averaged cross-shore current; $q_{0}=$ wave overtopping rate at the landward end $x=x_{m}$; and $q_{S}=$ volume flux per unit alongshore length associated with the water volume change between the still water shoreline and location $x$ due to the temporal change of $S$ which is assumed to be horizontal between $x=0$ and $x_{S W L}$. The first term in Eq. (1) is the wave-induced onshore volume flux and $\bar{U}$ is the return (undertow) current which is modified by $q_{0}$ and $q_{S}$. The cross-shore tidal current $\left(q_{S} / \bar{h}\right)$ is proportional to $\left(x_{S W L}-x\right) / \bar{h}$ which increases with the decrease of the bottom slope. This tidal current is important on a gently-sloping beach with a large tidal range in a low wave energy environment (e.g., Yamada and Kobayashi 2007).

The alongshore momentum equation in the wet zone is modified as

$$
\frac{d S_{x y}}{d x}=-\rho g \bar{h} \frac{\partial S}{\partial y}-\tau_{b y} \quad \text { for } \quad x<x_{S W L}
$$

where $S_{x y}=$ shear component of the wave-induced radiation stress; $\rho=$ fluid density; and $\tau_{b y}=$ timeaveraged alongshore bottom shear stress. The alongshore gradient of the water level $S$ is estimated using the tide data as explained in relation to Fig. 6. Farhadzadeh et al. (2012) included the alongshore pressure gradient term in Eq. (2) to predict the longshore current and sediment transport rate in a wave basin with a recirculation system for which the time-invariant value of $\partial S$ / $\partial y$ was in the range of $-1.2 \times 10^{-4}$ to 0.0 . For the present field data, the value of $\partial S / \partial y$ in Eq. (2) is associated with the alongshore tidal variation and varies hourly within the range of about $-10^{-5}$ to $10^{-5}$. This additional term is expected to be important in a low wave energy environment and near a coastal inlet.

The permeability of sand beaches has been neglected in the previous comparisons of CSHORE with the data. Wave overtopping of a sand dune results in an intermittent flow on an unsaturated sand surface. Infiltration of the flow into the sand may not be negligible landward of the dune crest. In the zone seaward of the dune crest, both infiltration and exfiltration occur and the interaction of the flows above and below the permeable bottom needs to be accounted for. The option in CSHORE for the permeable bottom assumes the presence of an impermeable lower boundary for the permeable layer (Kobayashi et al. 2010) but most sand beaches do not have impermeable lower boundaries. The following analysis is limited to infiltration into the sand layer of sufficient thickness landward of the dune crest located at $x=x_{c}$ where $x_{c}>x_{\text {SWL }}$.

In the wet and dry zone of $x>x_{S W L}$, the wave angle $\theta$ is assumed to be small and $(\sin \theta)^{2} \ll 1$. The continuity and cross-shore momentum equations in the zone for $x>x_{c}$ are expressed as

$$
\begin{aligned}
& \frac{d}{d x}(\overline{h U})=-P_{w} w_{m} \\
& \frac{d}{d x}\left(\overline{h U^{2}}+\frac{g}{2} \overline{h^{2}}\right)=-g \bar{h} \frac{d z_{b}}{d x}-\frac{\tau_{b x}}{\rho}-\alpha P_{w} w_{m}(g \bar{h})^{0.5}
\end{aligned}
$$


where $h$ and $U$ = instantaneous water depth and cross-shore velocity, respectively, with the overbar indicating averaging for the wet duration; $P_{w}=$ wet probability defined as the ratio between the wet and entire durations; $w_{m}=$ maximum downward seepage velocity due to the gravity force given by Kobayashi et al. (2010); $z_{b}=$ bottom elevation corresponding to the sand surface; $\tau_{b x}=$ time-averaged cross-shore bottom shear stress; and $\alpha=$ constant of approximately 2 involved in the relation between $U$ and $h$. Eqs. (3) and (4) are similar to those used by Kobayashi et al. (2010). The term on the right hand side of Eq. (3) is the infiltration rate into the sand surface. The last term on the right hand side of Eq. (4) is the flux of the horizontal momentum into the sand layer. Exfiltration of the infiltrated water and momentum are not considered in Eqs. (3) and (4). In the zone of $x_{S W L}<x<x_{c}$, the impermeable bottom is assumed and use is made of Eqs. (3) and (4) with $w_{m}=0$. Eqs. (3) and (4) may be crude but allow the assessment of the permeability effect on wave overwash. The maximum downward seepage velocity $w_{m}$ for the sand with the median diameter of $0.31 \mathrm{~mm}$ is calculated to be $0.04 \mathrm{~cm} / \mathrm{s}$. The value of $w_{m}$ was $1.2 \mathrm{~cm} / \mathrm{s}$ for the gravel with the median diameter of $2.0 \mathrm{~mm}$ in the gravel beach experiment by Kobayashi et al. (2011). Consequently, the permeability effect for the $0.31 \mathrm{~mm}$ sand is expected to be relatively small.

\section{Comparison of Numerical Model with Field Data}

The expanded numerical model is compared with the profile evolutions during periods E1, A1, and E2 with no nourishment. The input empirical parameters in the model are taken as the same as those used by Kobayashi and Jung (2012) who reproduced the beach erosion and recovery above MSL on the straight Rehoboth and Dewey Beaches during 1992 to 1993 before the start of the nourishment of these beaches. They calibrated the bed load coefficient $B=0.001$ for the beach erosion and $B=0.002$ or $B=0.003$ for the beach recovery. The beach profile evolutions during periods E1, A1, and E2 are computed using $B=0.001$ and $B=0.002$. The agreement between the measured and computed final profiles for E1 and E2 is better for $B=0.001$. The agreement for A1 is better for $B=0.002$. The measured accretion volumes per unit alongshore length above MSL for A1 varied in the range of -13 (erosion) to 29 (accretion) $\mathrm{m}^{3} / \mathrm{m}$. These volumes were small relative to the erosion volumes for E1 and E2 listed in Table 2. The comparisons for E1 and E2 are presented in the following because the performance of the nourished Bethany Beach was affected mostly by the two severe storms shown in Figs. 2 and 4.

Fig. 7 shows the measured and computed final profiles and the measured initial profile for periods E1 and E2 along line N30. The berm erosion above MSL for E1 is predicted well but the deposition below MSL is overpredicted. The dune erosion for E2 is underpredicted but the berm erosion is overpredicted. The deposition below MSL for E2 is predicted better. The comparisons for other crossshore lines are presented in the report by Do et al. (2012). The numerical model does not predict the detail of the profile change but predicts the eroded profiles measured after the two different storms with similar accuracy.

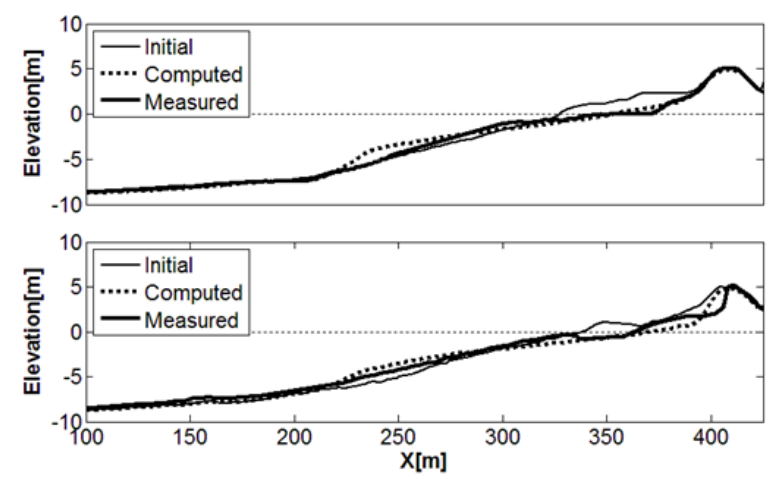

Figure 7. Measured and computed final profiles starting from initial profile for period E1 (top) and E2 (bottom) along line N30. 
The computed longshore sediment transport rate is integrated with respect to time and spatially from $x=0$ to $x=x_{m}$ to obtain the sand volume (no void) transported alongshore during each period. The computed sand volumes for E1 and E2 are shown as a function of the northward alongshore distance $y$ from line N00 in Fig. 8. The negative volume implies the southward longshore sediment transport which is consistent with the observed wave directions shown in Figs. 2 and 4. The sand volumes transported southward during E1 and E2 increase from line N60 to N00. This southward increase causes the sand volume loss between lines N60 and N00. The sand volume transported southward is larger during E2 because the storm for E2 (Fig. 4) lasted longer than the storm for E1 (Fig. 2). It is noted that we expected the northward longshore sediment transport on Bethany Beach on the basis of previous predictions of the nodal point location on the Delaware-Maryland coast (e.g., Puleo 2010). These predictions were based on hindcast waves from 20 years (1956-1975, 1976-1993 or 1980-1999) of wave information study (WIS) data. This study is limited to the beach of $1.8 \mathrm{~km}$ length and the 3-year (2007-2010) wave gauge data.

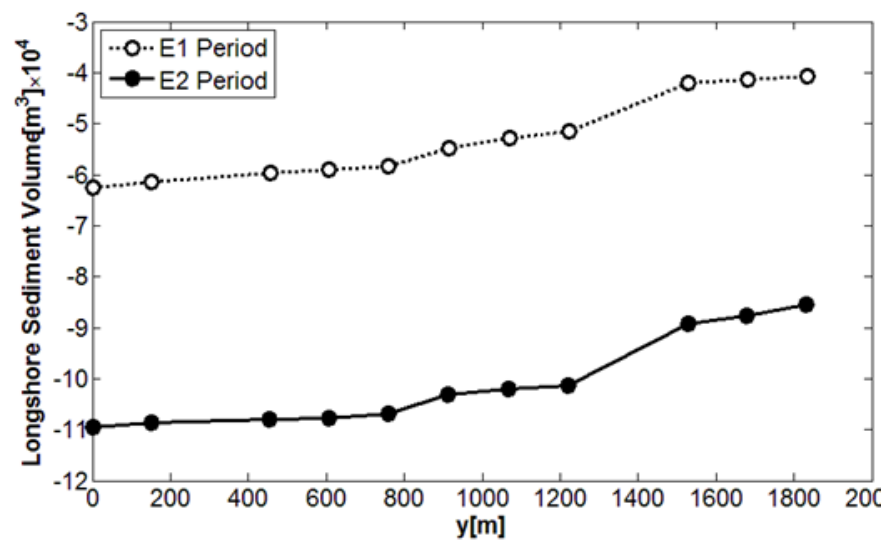

Figure 8. Computed sand (no void) volume transported alongshore during period E1 (77 days) and E2 (88 days).

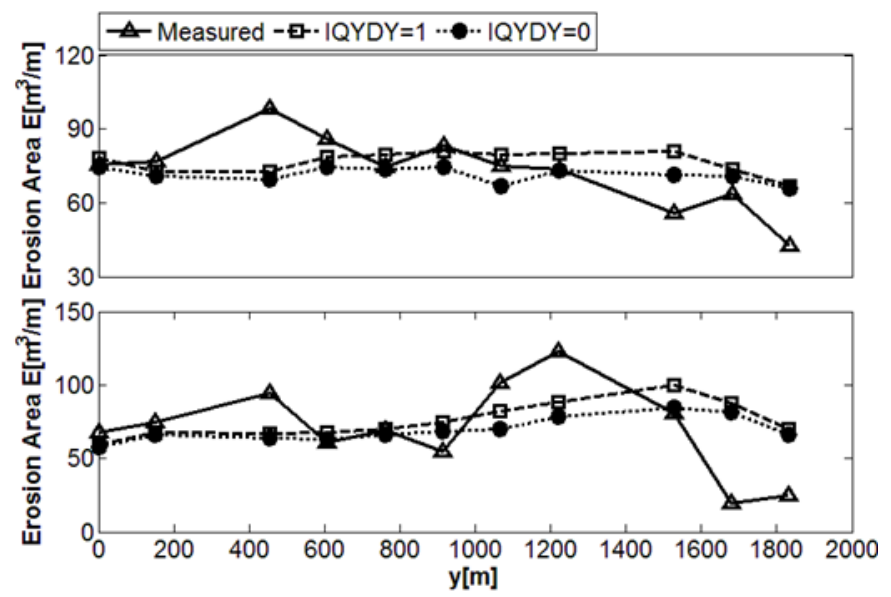

Figure 9. Measured and computed (IQYDY=1 and 0 ) erosion volume above MSL per unit alongshore length during period E1 (top) and E2 (bottom) where the effects of tidal currents (ITIDE=1 and 0 ) and infiltration (INFILT=1 and 0 ) are negligible and not plotted.

Fig. 9 shows the measured and computed erosion volumes above MSL per unit alongshore length for E1 and E2 where the measured volumes are listed in Table 2. The computational option of IQYDY=1 includes the effect of the alongshore gradient of the longshore sediment transport rate on the cross-shore profile evolution. This effect is not included for IQYDY $=0$. The larger erosion volume for IQYDY=1 is consistent with the southward increase of the southward sediment transport volume in Fig.8. The erosion volumes at lines N55 and N60 are overpredicted. The nourished volumes in Table 2 
are smaller at these lines. The cause of the reduced erosion is uncertain and might be related to the gentler bottom slope along these lines with the larger values of $x_{m}$ in Table 2. The seaward boundary $x=0$ of each line is located in water depth of approximately $10 \mathrm{~m}$. The incident waves at $x=0$ are assumed to be the same for all the lines. The wave transformation along each line is computed assuming the alongshore uniformity of the bathymetry. Another possible cause might be the alongshore variation of the sand size induced by the computed alongshore variation of the longshore sediment transport rate in Fig. 8.

Computations are also made for the option of ITIDE $=1$ and 0 as well as INFILT $=1$ and 0 . For ITIDE=0, $\partial S / \partial t=0$ in Eq. (1) and $\partial S / \partial y=0$ in Eq. (2). For INFILT=0, $w_{m}=0$ in Eqs. (3) and (4). The default options in this study are IQYDY=1, ITIDE=1, and INFILT=1. The comparisons of the computed final profiles for IQYDY=1 and 0 along the 11 lines indicate increased vertical erosion for IQYDY=1 up to $0.6 \mathrm{~m}$ for $\mathrm{E} 1$ and $1.0 \mathrm{~m}$ for E2. The elevation differences of the final profiles between ITIDE $=1$ and 0 are in the range of -2 to $3 \mathrm{~cm}$ for $E 1$ and -1 to $3 \mathrm{~cm}$ for E2. The tidal effect is computed to cause local erosion up to $2 \mathrm{~cm}$ and local accretion up to $3 \mathrm{~cm}$. The elevation differences of the final profiles between INFILT $=1$ and 0 are less than $0.2 \mathrm{~cm}$. The tidal and infiltration effects turn out to be negligible for Bethany Beach. The tidal effect is expected to become more important for a beach with a gentler slope and a larger tidal range in a low wave energy environment. The infiltration effect may become more noticeable for a dune composed of a coarser sediment.

Finally, the effect of the sand size on the performance of the nourished beach is examined to assist future nourishment projects. The computations made above are based on the median diameter of 0.31 $\mathrm{mm}$ and its fall velocity of $4.17 \mathrm{~cm} / \mathrm{s}$. The sediment diameter and fall velocity corresponding to the 16 and 84 percent finer by weight in Table 3 are used as input to the numerical model to represent hypothetical finer and coarser sands. Fig. 10 shows the computed sand volume transported alongshore for the sand diameters of $0.23,0.31$ and $0.45 \mathrm{~mm}$ for E1 and E2. The sand volume transported southward decreases with the increase of the sand diameter. The degree of the volume change is similar to the degree of the diameter change. The corresponding erosion volume above MSL per unit alongshore length is shown in the same manner as in Fig. 8 which shows the measured volume. The erosion volume above MSL decreases with the increase of the sand diameter as expected. The alongshore variability of the measured erosion volume is approximately within the range of the eroded volumes for the diameters of 0.23 and $0.45 \mathrm{~mm}$. The use of the coarser sand of $0.45 \mathrm{~mm}$ reduces the erosion volume above MSL caused by the two severe storms, which resulted in the repair nourishment as indicated in Table 1. The longevity of the placed sand and the reduced frequency of the eroded beach repair will reduce the cost of the nourishment project.

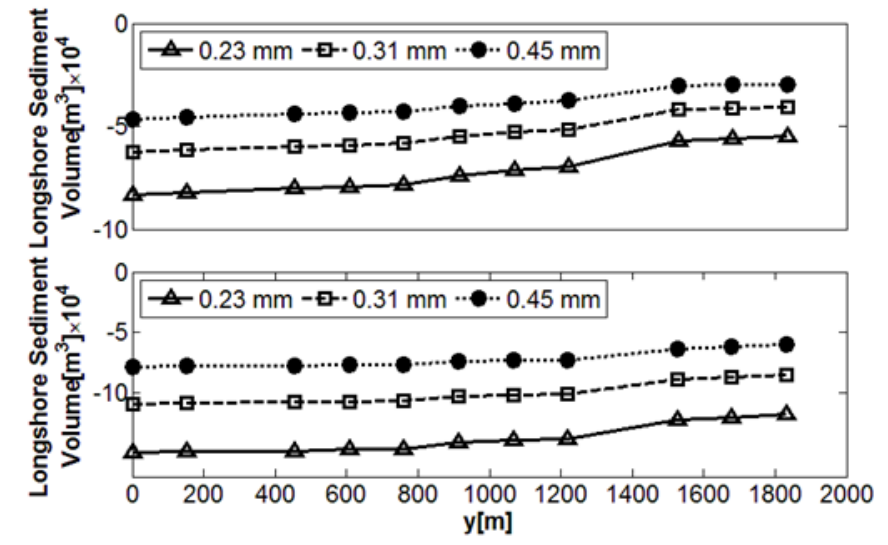

Figure 10. Computed sand volume transported alongshore for median diameters of $0.23,0.31$ and $0.45 \mathrm{~mm}$ during period E1 (top) and E2 (bottom). 


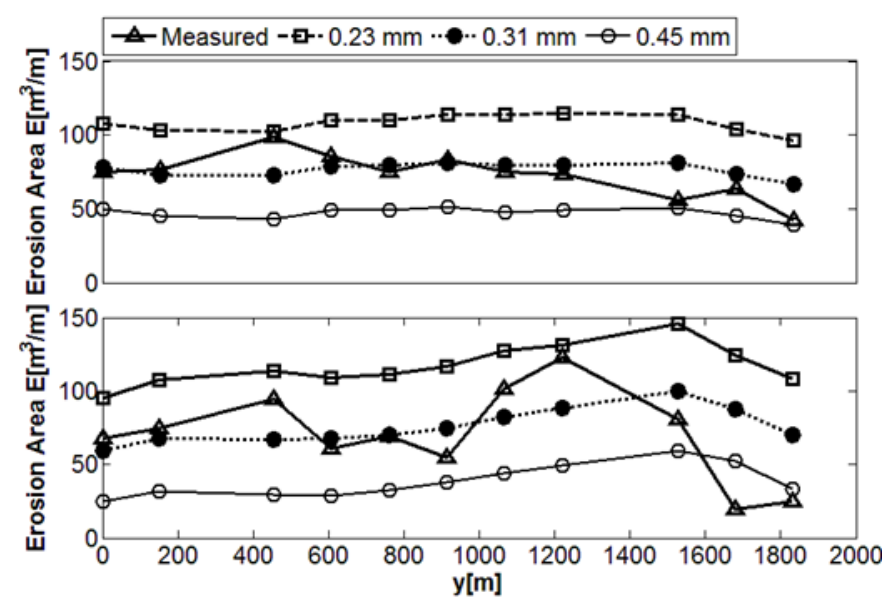

Figure 11. Computed erosion volume above MSL per unit alongshore length for median diameters of 0.23 , 0.31 and $0.45 \mathrm{~mm}$ during period E1 (top) and E2 (bottom).

\section{Summary and Conclusions}

The beach profiles measured along 13 cross-shore lines seven times during September 2007 to September 2010 are analyzed to examine the performance of the nourished beach of $1.8 \mathrm{~km}$ length on Bethany Beach in Delaware. The nourished volume per unit alongshore length of the sand with its median diameter of $0.31 \mathrm{~mm}$ was about $500 \mathrm{~m}^{3} / \mathrm{m}$. The hourly time series of the incident wave height, period and direction in water depth of approximately $10 \mathrm{~m}$ are obtained from available wave gauge data. Available tide gauge data are analyzed to obtain the hourly time series of the still water level $S$ above MSL and the alongshore gradient of $S$. The nourished beach was attacked by two severe storms in May 2008 and November 2009. The recovery after the first storm was insufficient and the eroded berm above MSL was repaired. The second storm with a longer duration eroded the dune partially but did not erode the beach down to the elevation of the beach before the major nourishment.

The cross-shore numerical model CSHORE with multiple cross-shore lines is used to estimate the cross-shore and longshore sediment transport during the two erosion periods along the curved shoreline of Bethany Beach. The model is expanded to include cross-shore and longshore tidal currents and infiltration of overtopping water into the sand landward of the dune crest. The tidal and infiltration effects turn out to be negligible for Bethany Beach but may become appreciable for other beaches. The sand volume transported southward is computed to increase along the curved shoreline. The alongshore gradient of the longshore sand transport volume causes beach erosion on Bethany Beach. The majority of erosion above MSL during the two storms is predicted to be caused by the offshore sand transport. The numerical model calibrated using field data from straight beaches is shown to reproduce the profile changes during the two erosion periods with similar accuracy (a factor of about 2). The performance of the nourished beach by placing finer and coarser sands with 0.23 and $0.45 \mathrm{~mm}$ diameters is computed to examine the sensitivity of the sand size. The increase of the sand diameter significantly reduces the longshore sand transport and the beach erosion above MSL for the two erosion periods. Additional field data are required to confirm the computed sensitivity to the sand size. The spatial and temporal variations of the sand size may need to be predicted to improve the accuracy of the numerical model because of the sensitivity.

\section{ACKNOWLEDGMENTS}

This research was supported by Basic Science Research Program through the National Research Foundation of Korea(NRF) funded by the Ministry of Education, Science and Technology(40020100155). This research was partially supported from "Storm-surge inundation prediction and hazard map" from the Korea Institute of Ocean Science \& Technology. The first author thanks the Center for Applied Coastal Research of University of Delaware for its hospitality during his one-year stay. The writers thank Mr. Randy Wise for providing the beach profile data used in this study. 


\section{REFERENCES}

Dean, R.G. (1991). Equilibrium beach profiles: Characteristics and applications, J. Coastal Res., 7(1), 53-84.

Do, K., Kobayashi, N., and Suh, K.D. (2012). Performance of Bethany Beach nourishment project against two severe storms in 2008 and 2009, Res. Rep. No. CACR-12-01, Center for Applied Coastal Research, Univ. of Delaware, Newark, Del.

Farhadzadeh, A., Kobayashi, N., and Gravens, M.B. (2012). Longshore sediment transport due to breaking waves and external current, J. Waterway, Port, Coastal, Ocean Eng., (in press).

Figlus, J. and Kobayashi, N. (2008). Inverse estimation of sand transport rates on nourished Delaware beaches, J. Waterway, Port, Coastal, Ocean Eng., 134(4), 218-225.

Jiménez, J. and Madsen, O.S. (2003). A simple formula to estimate settling velocity of natural sediments, J. Waterway, Port, Coastal, Ocean Eng., 129(2), 70-78.

Kobayashi, N. and Jung, H. (2012). Beach erosion and recovery, J. Waterway, Port, Coastal, Ocean Eng., (accepted).

Kobayashi, N., Farhadzadeh, A., and Melby, J.A. (2010). Wave overtopping and damage progression of stone armor layer, J. Waterway, Port, Coastal, Ocean Eng., 136(5), 257-265.

Kobayashi, N., Hicks, B.S., and Figlus, J. (2011). Evolution of gravel beach profiles, J. Waterway, Port, Coastal, Ocean Eng., 137(5), 258-262.

Kobayashi, N., Buck, M., Payo, A., and Johnson, B.D. (2009). Berm and dune erosion during a storm, J. Waterway, Port, Coastal, Ocean Eng., 135(1), 1-10.

Puleo, J.A. (2010). Estimating alongshore sediment transport and the nodal point location on the Delaware-Maryland coast, J. Waterway, Port, Coastal, Ocean Eng., 136(3), 135-144.

Ramsey, K.W. (1999). Beach sand textures from the Atlantic coast of Delaware, Open File Rep. No. 41, Delaware Geological Survey, Newark, Del.

U. S. Army Engineer Research and Development Center. (2002). Coastal Engineering Manual, Part III, Coastal Sediment Processes, Coastal and Hydraulics Lab., Vicksburg, Miss.

Yamada, F. and Kobayashi, N. (2007). Intertidal multiple sand bars in a low-energy environment, J. Waterway, Port, Coastal, Ocean Eng., 133(5), 343-351. 